\title{
Índices zootécnicos e produtivos em rebanho leiteiro, $\mathrm{CCA} / \mathrm{UFPB}^{1}$
}

\author{
Tacieli Beserra Britto Gomes ${ }^{2}$, Severino Gonzaga Neto ${ }^{3}$, Carla Giselly de Souza ${ }^{4}$, Natália Jamylle \\ Germano Gomes ${ }^{5}$, Renato Tonhá Alves Junior ${ }^{6}$, Pedro Henrique Borba Pereira ${ }^{7}$, Carlos Augusto de \\ Almeida Targino Alcoforado ${ }^{8}$
}

\begin{abstract}
Resumo: O objetivo da pesquisa foi avaliar índices zootécnicos e produtivos do rebanho leiteiro do departamento de zootecnia/CCA/UFPB. O estudo foi realizado no Setor de Bovinocultura de Leite do CCA/UFPB em Areia-PB, localizado na mesorregião do agreste da Paraíba. Foram utilizados registros das fichas de controle leiteiro e controle reprodutivo do rebanho. O rebanho é composto por vacas mestiças Europeu/Zebu 3/4, com média de 29 vacas em lactação por ano, entre os anos de 2008 a 2016. A média da produção de leite de cada controle foi calculada e consequentemente a média dos meses de lactação do rebanho. Os dados foram submetidos a análise pelo teste $\mathrm{F}(\mathrm{p} \leq 0,05)$ e o teste de Tukey. Os anos de 2008 e 2009 apresentaram dados inferiores aos demais. A partir do ano 2010 os índices zootécnicos e produtivos melhoraram com a presença de um técnico. A produção total na lactação do rebanho mostrou-se significativa, com uma boa média de produção anual, a duração da lactação na maioria dos anos apresentou- se dentro do que é preconizada para a raça, a persistência média do rebanho na maioria dos anos encontra-se abaixo do que é preconizado. Estatisticamente não foram observadas diferenças significativas com relação ao intervalo de partos e a média de produção de leite por intervalo de parto. Foi possível constatar que os índices precisam ser melhorados.
\end{abstract}

Palavras chaves: duração da lactação; intervalo de partos; persistência de lactação.

\section{Zootechnical and productive indexes in dairy herd, From Federal University Of Paraiba, CCA / UFPB}

\begin{abstract}
The objective of this research was to evaluate zootechnical and productive indexes of the Dairy herd from the Animal Science Department / CCA/ UFPB. The study was carried out in the Dairy Cattle Sector of the CCA / UFPB in AreiaPB, located in the Agreste's mesoregion from Paraiba- Brazil. Dairy and reproductive control records were used. The herd is composed of European / Zebu crossbred cows, with an average of 29 lactating cows per year between 2008 and 2016. The average milk yield of each control was calculated and, consequently, the herd average lactation months. The data were analyzed by the F test $(\mathrm{p} \leq 0.05)$ and the Tukey test. The years 2008 and 2009 presented lower data than the others. From the year 2010 the zootechnical and productive indexes improved with the presence of a technician. The herd total lactation production was significant, with a good average annual production, the lactation duration in most years was within the range recommended for the breed, the herd average persistence in most years found below what is expected. Statistically no significant differences were observed in relation to the calving interval and the average milk yield per calving interval. It was possible to see that the indexes need to be improved.
\end{abstract}

Key words: interval between deliveries; lactation duration; persistence of lactation.

\footnotetext{
${ }^{1}$ Submetido em 13/12/2018 e aprovado em 14/04/2019

${ }^{2}$ Zootecnista; Universidade Federal da Paraíba (UFPB), Centro de Ciências Agrárias, Areia-PB, CEP: 58.397-000; E-mail: tacielibeserra@hotmail.com

${ }^{3}$ Doutor em Zootecnia; Professor Associado, Universidade Federal da Paraíba (UFPB), Centro de Ciências Agrárias, Programa de PósGraduação em Zootecnia (PPGZ), Areia-PB, CEP: 58.397-000; E-mail: sgonzaganeto@gmail.com

${ }^{4}$ Doutora em Zootecnia; Bolsista de Pós-Doutorado, Universidade Federal Rural de Pernambuco (UFRPE), Recife-PE, CEP: 52.171-900; Email: carlaxlsouza@yahoo.com.br

${ }^{5}$ Zootecnista; Universidade Federal da Paraíba (UFPB), Centro de Ciências Agrárias, Areia-PB, CEP: 58.397-000; E-mail: germanojamylle@gmail.com

${ }^{6}$ Meste em Ciência Animal e Pastagens; Doutorando, Universidade Federal da Paraíba (UFPB), Centro de Ciências Agrárias, Programa de PósGraduação em Zootecnia, Areia-PB, CEP: 58.397-000; E-mail: renato_rtj@hotmail.com

${ }^{7}$ Graduando em Zootecnia, Universidade Federal da Paraíba (UFPB), Centro de Ciências Agrárias, Areia-PB, CEP: 58.397-000, E-mail: pedro.borba.pereira@gmail.com

${ }^{8}$ Mestre em Zootecnia; Zootecnista do Setor de Bovinocultura, Universidade Federal da Paraíba (UFPB), Centro de Ciências Agrárias, AreiaPB, CEP: 58.397-000; E-mail: catargino@ hotmail.com
} 


\section{Introdução}

A produção de leite no Brasil em sua maioria advém do sistema de criação extensivo. Por este os produtores brasileiros buscaram animais mais adaptados ao clima tropical, através do cruzamento entre as raças zebuínas e taurinas, destacando-se o cruzamento da raça Gir com a Holandesa, dando origem à raça Girolando, onde foi possível obter animais mais adaptados e produtivos, pleiteando-se a rusticidade da raça Gir e a produtividade leiteira da raça Holandesa (EMBRAPA, 2010).

Segundo Salgado et al. (2016), o cruzamento do gado bovino Girolando começou por volta da década de 1940, em Minas Gerais. Os animais oriundos deste cruzamento se destacaram quanto à rusticidade, precocidade $\mathrm{e}$, principalmente, pela boa produção do leite. Assim, passou-se a buscar a heterose, complementaridade decorrente da contribuição das características desejáveis de cada raça, como também a precocidade advinda da redução do tempo para a incorporação dos genes que apresentam maior valor econômico (Santos, 2012).

$\mathrm{Na}$ exploração de vacas leiteiras deve-se estabelecer índices de produtividade, avaliando os mesmos para caracterizar os sistemas de produção, adotados por um país, região ou mesmo uma fazenda produtora de leite. A produção de leite e os aspectos reprodutivos são os índices mais importantes, pois são processos definitivos na eficácia da produção dos rebanhos leiteiros pelos seus reflexos diretos na produtividade e rentabilidade (Moreira, 2012).

Atualmente, o Brasil encontra-se em quarto lugar no ranking mundial de produção de leite (Zoccal, 2017), sendo o genótipo Girolando responsável por cerca de $80 \%$ do volume total de leite produzido no País (Salgado et al., 2016). Segundo Jacopini et al. (2012) a produção de leite é afetada por fatores como raça, ordem de lactação, composições genéticas, sendo utilizados diversos modelos matemáticos na tentativa de ajustar os dados e descrever a curva de lactação com precisão.

A persistência da lactação é uma das principais características que definem a forma da curva de lactação, tendo uma enorme correlação com a produção inicial, o período ascendente da produção ou o tempo do pico e, sobretudo, com a produção do pico (Santos, 2012). Para que se possa medir a produtividade do sistema de produção de leite brasileiro são usadas as médias de produção e a curva de lactação. Este estudo da produção da lactação poderá contribuir para que o produtor rural tenha maior entendimento da previsão de produção do rebanho, estágios de lactação, manejo em cada fase produtiva, para tomadas de decisão num momento de necessidade de descarte.

A duração da lactação na maioria das fazendas brasileiras é desconhecida, onde produtores muitas vezes mantêm as vacas em lactação além do tempo recomendado ou mantêm no rebanho vacas secas que apenas geram despesas (Bergamaschi et al., 2010), pois no primeiro caso explora-se a vaca além de seus limites e no segundo gastam com alimentos mantendo uma vaca que não está mais produzindo leite. Deste modo, registrar a produção de leite, por meio de controles leiteiros, observar o comportamento produtivo e calcular a produção média de leite, por vaca e por intervalo de parto, são maneiras de melhorar a produtividade do rebanho e reduzir o custo médio ao produtor.

O Brejo Paraibano possui características naturais propícias à produção de leite. No entanto, não é explorada pelos produtores de maneira eficiente. Observa-se, nas propriedades, rebanhos compostos por animais com padrão racial e boa capacidade produtiva, porém, em sua maioria, submetidos a manejo precário, fazendo com que os animais não expressem o seu potencial produtivo. Tal situação poderia ser revertida através da implantação de um controle zootécnico eficiente (produtivo e reprodutivo), como também a realização de um planejamento estratégico para as diferentes épocas do ano, com especial atenção à reserva de volumoso (silagem ou feno), para suprir o déficit de forragem no período seco.

Com esta pesquisa, objetivou-se avaliar índices zootécnicos e produtivos do rebanho leiteiro do Departamento de Zootecnia, do Centro de Ciências Agrárias, da Universidade Federal da Paraíba, município de Areia, PB.

\section{Material e Métodos}

O estudo foi conduzido no Setor de Bovinocultura de Leite $\left(6^{\circ} 58^{\prime} 26^{\prime \prime} \mathrm{S}, 35^{\circ} 43^{\prime} 14^{\prime \prime}\right.$ W Gr e a $565 \mathrm{~m}$ acima do nível do mar) do Centro de Ciências Agrárias, da Universidade Federal da 
Paraíba, município de Areia-PB. O município está localizado na mesorregião do agreste da Paraíba, microrregião do brejo paraibano, com temperatura média anual de $23^{\circ} \mathrm{C}$, sendo a temperatura média mínima de $19,1^{\circ} \mathrm{C}$ e a temperatura máxima média de $26,9^{\circ} \mathrm{C}$ com um índice pluvial médio anual de $1.425 \mathrm{~mm}$ (Gondim e Fernandes 1980). A média anual da umidade relativa do ar é de $80 \%$, e velocidade do ar é de $2,5 \mathrm{~m} \mathrm{~s}^{-1}$. O clima da área, segundo a classificação de Köppen, é do tipo As' (quente e úmido) com chuvas de outono-inverno, com período de estiagem de 5 a 6 meses.

Os dados meteorológicos foram obtidos de forma convencional através do banco de dados da Estação Meteorológica do município de Areia, onde foi utilizado o somatório da precipitação pluviométrica $(\mathrm{mm})$, para posteriores analises com os demais dados.

Foram utilizados registros das fichas de controle leiteiro e controle reprodutivo do rebanho composto de vacas mestiças Europeu/Zebu com uma taxa de grau de sangue de $75 \%$ europeu e $25 \%$ zebu, com média de 29 vacas em lactação por ano, entre os anos de 2008 à 2016. Foi calculada a média da produção de leite de cada controle e consequentemente a média dos meses de lactação do rebanho.

$\mathrm{O}$ controle leiteiro foi realizado a cada vinte e oito dias no período entre 2008 e 2016 e a produção de leite determinada em massa nos dois turnos (manhã e tarde). A partir destes registros foram extraídos dados da produção de leite e data do parto, calculou-se a produção de leite durante a lactação, a média diária, média mensal, dias em lactação, média de dias em lactação, intervalo entre parto, média em dias de intervalo de partos e persistência média.

Os dados foram comparados pelo Teste $\mathrm{F}(\mathrm{p} \leq$ $0,05)$. Também foram utilizados modelos de regressão aleatória para avaliar a persistência na lactação, devido sua habilidade em separar a curva de lactação para cada animal. Para calcular a Persistência da Lactação (PSL) utilizou-se a seguinte fórmula (Dellaqua, 2015):

$$
\mathrm{PSL}=[1-((\mathrm{PL} \text { ant }-\mathrm{PL} \text { post }) \times(30 / \text { IECL }) / \mathrm{PLant})] \times 100
$$

Onde: $\mathrm{PL}_{\text {ant }}$ é a produção de leite anterior (produção de leite do mês anterior), $\mathrm{PL}_{\text {post }}$ é a produção de leite posterior (produção do leite do mês atual), IECL é o intervalo em dias entre os controles leiteiros.

\section{Resultados e Discussão}

Na Tabela 1 observam-se as variáveis que foram analisadas para a produção total na lactação $(\mathrm{kg})$, a média da produção anual $(\mathrm{kg})$, a duração da lactação (dias), a persistência média (\%), o intervalo de partos (dias), a média do intervalo de partos (meses) e a precipitação pluviométrica $(\mathrm{mm})$. A produção total na lactação do rebanho mostrou-se significativa, visto que o sistema de criação é semi-intensivo, ou seja, os animais passam mais tempo no pasto e recebem uma suplementação após a ordenha, e com isto a precipitação pluviométrica irá influenciar diretamente a qualidade da pastagem, que não teve o mesmo desempenho em todos os anos e também a quantidade de animais variou entres os anos, porém a área de pastejo foi a mesma.

A implementação de mão de obra qualificada é imprescindível na melhoria dos índices zootécnicos de qualquer rebanho. No caso específico de um rebanho leiteiro, a melhoria de um manejo reprodutivo e nutricional foram fundamental na melhoria da produção total da lactação e a média de produção anual de leite. Sem falar da qualidade do leite produzido e da saúde geral das vacas em questão.

A média da produção anual foi boa (3782 litros/vaca/ano), onde todos os anos apresentouse superior à média nacional (aproximadamente 1600 mil litros/vaca/ano) (SNA 2017), o que nos mostra que a produção individual do rebanho está acima do que se preconiza para o pais.

A duração da lactação na maioria dos anos apresentou- se dentro do que é preconizado para a raça. Segundo a Embrapa (2017), a lactação tende a ser menor para rebanhos mestiços, com duração de 270 a 290 dias. A persistência média do rebanho na maioria dos anos encontra-se abaixo do que é preconizado. Para vacas não especializadas considera-se $80 \%$ uma boa persistência (Fundação Roger, 2017)

Estatisticamente não foram observadas diferenças significativas com relação ao intervalo de partos e a média de produção de leite por intervalo de parto. A média de intervalo de parto é de 15 meses o que está acima do que se deseja pra obter um parto por ano, que seria de no máximo 14 meses de intervalo de parto. 
Já com relação à média de produção de leite por intervalo de parto, embora não tenha se observado diferença entre os anos, nota-se nos anos de 2008 e 2009 médias muito baixas, porém, a partir de 2010, essa média apresentou-se superior a $20 \%$, ficando praticamente estável nos anos seguintes.

Nota-se que os anos de 2008 e 2009 apresentaram índices inferiores quando comparados aos demais anos. Pois, a partir do ano 2010 os índices zootécnicos e produtivos melhoraram com a intervenção de um técnico que melhorou o manejo sanitário já existente, e implementou calendário de controle de endo e ectoparasitos, higiene do manejo, vacinação e outros.

Onde o manejo nutricional melhorou com base na formulação de dietas balanceadas (a base de farelo de soja $30 \%$, fubá de milho $60 \%$, trigo $8 \%$ e mistura mineral $2 \%$ ) na proporção de $1 \mathrm{~kg}$ de matéria natural para cada $1 \mathrm{~kg}$ de leite produzido que atendem as exigências dos animais (Tabela 2), sendo ofertado de acordo com a produção de leite de cada animal.

Tabela 2 Composição bromatológica das dietas implementadas com a presença do técnico

\begin{tabular}{ll}
\hline \multicolumn{2}{c}{ Composição da Dieta } \\
\hline Matéria seca (MS) & $14,20 \mathrm{~kg}$ \\
Fibra bruta (FB) & $21,5 \%$ \\
Fibra em detergente neutro (FDN) & $38,35 \%$ \\
Fibra em detergente ácido (FDA) & $22,47 \%$ \\
Proténa Bruta (PB) & $15,48 \%$ \\
Extrato etéreo (EE) & $1,19 \%$ \\
Carboidrato não fibroso & $16,22 \%$ \\
NDT & $71,5 \%$ \\
\hline
\end{tabular}

Também houve melhoria no manejo das pastagens, com a utilização de adubação, irrigação e a divisão em piquetes, o que contribuiu significativamente para aumentar a oferta de forragem ao longo do ano.

Porém se constatou através dos registros referentes à produção e a reprodução utilizados no controle zootécnico, que os índices precisam ser melhorados, fato comprovado pelos dados acima, onde se verificou possíveis falhas no manejo produtivo e reprodutivo do rebanho.

Pode ter havido falha na observação do cio, pois se utiliza um rufião, porém ele não tem marcador, o que torna a observação do cio apenas visual implicando em um maior intervalo de

Revista Agropecuária Técnica, Areia-PB, v. 39, n. 4, p. 333-338, 2018

DOI: $10.25066 /$ agrotec.v39i4.42157 
partos. Por isso o uso da inseminação artificial com tempo fixo (IATF) pode minimizar este problema.

O manejo pré e pós-parto irá influenciar diretamente nestes resultados, pois os animais deveriam estar em boa condição corporal ao parirem e após o parto independente da sua produção deveriam receber a mesma suplementação dos animais mais produtivos fazendo com que diminuísse o efeito do balanço energético negativo.

O material genético do rebanho é bom visto que nos anos de 2010 e 2014 alcançaram uma boa persistência, porém há uma alternância no padrão genético, pois os animais puros são mais susceptíveis aos ectoparasitas hematófagos (carrapatos).

\section{Conclusão}

A evolução dos dados produtivos deu-se através da implantação de um controle zootécnico mais eficiente no rebanho, especialmente, após a atuação de um Zootecnista na referida unidade de produção, o qual implantou melhorias no manejo nutricional, reprodutivo e sanitário, resultando em melhores índices produtivos entre os anos avaliados. A melhoria ou adequação dos manejos reprodutivo e nutricional são práticas extremamente recomendadas para o incremento da saúde e produtividade de um rebanho leiteiro.

\section{Referências}

Bergamaschi, M. A. C. M.; Machado, R.; Barbosa, R.T. Eficiência reprodutiva das vacas leiteiras. Circular Técnica, 64. EMBRAPA São Carlos, SP, 2010.

Chaves, L. C. S. Avaliação da persistência da lactação em vacas Girolando utilizado modelos de regressão aleatória. 2005. $86 \mathrm{f}$. Tese - Universidade Federal de Viçosa, Minas Gerais, 2005.

Cobuci, J. A.; Euclydes, R. F.; Costa, C. N. Lopes, P. S.; Torres, R. A.; Pereira, C. S. Análises da persistência na lactação de vacas da raça holandesa, usando produção no dia do controle e modelo de regressão aleatória. Revista Brasileira de Zootecnia, v.33, n.3, p.546-554,

2004.
Croce, E. J. G. D. Conheça seus animais avaliando a curva de lactação pelo IDEAGRI. Artigo Técnico IDEAGRI. 2009. Disponível em:

http://ideagri.com.br/plus/modulos/noticias/imprimir.php ?cdnoticia $=54$ >. Acesso em 05/10/2017

Dellaqua, J. V. T. Controle Leiteiro - Curva de Lactação. 2015. Disponível em: < http://www.coimma.com.br/balancas-etroncos/Controle leiteiro curva de lactacao.html >. Acesso em 11/12/2017.

EMBRAPA GADO DE LEITE. Tecnologia para produção de leite na região sudeste do país. 2017. Disponível em: < http://www.cnpgl.embrapa.br/sistemaproducao/1tecnologia-para-produ\%C3\%A7\%C3\%A3o-de-leite-naregi\%C3\%A3o-sudeste-do-brasil $>$. Acesso em 10/10/2017.

EMBRAPA. Programa de melhoramento genético da raça girolando - teste de progênie: sumário de touros 2010. Juiz de Fora: Embrapa Gado de Leite, 2010.

Ferreira, A. M.; Miranda, J. E. C. Medidas de eficiência da atividade leiteira: índices zootécnicos para rebanhos leiteiros. Comunicado Técnico, 54. EMBRAPA - Juiz de Fora, MG, 2007.

Gondim, A. W. A; Fernandez, B. Probabilidade de chuvas para o município de Areia-PB. Agropecuária Técnica, v. 1, n.1, p. 55-63, 1980.

Freitas, M. S. Utilização de modelos de regressão aleatória na avaliação genética de animais da raça girolando. 2003. $77 \mathrm{f}$. Tese Universidade Federal de Viçosa, Minas Gerais, 2003.

IBGE (Instituto Brasileiro de Geografia e Estatística). Sistema IBGE de Recuperação Automática-SIDRA. 2016. Disponível em: < http://sidra.ibge.gov.br/tabela/74\#resultado $>$. Acesso em: 13/10/2017.

IEPEC. Tudo sobre a raça girolando na pecuária leiteira. 2016. Disponível em: < http://iepec.com/tudo-sobre-a-raca-girolando-na-pecuarialeiteira/ >. Acesso em: 10/10/2017

Jacopini, L. A.; Barbosa, S.B.P.; Lourenço, D.A.L.; Silva, M.V.G.B. Curvas de lactaçãa de vacas Girolando através de diferentes modelo. IX Simpósio Brasileiro de 
Melhoramento Animal. João Pessoa, PB. 20 a 22 de junho de 2012.

MILKPOINT. IBGE: produção de leite cai 2,9\% em 2016; pesquisa aponta aumento dos rebanhos bovinos. 2017 Disponível em: < https://www.milkpoint.com.br/cadeia-do-leite/girolacteo/ibge-producao-de-leite-cai-29-em-2016-pesquisaaponta-aumento-dos-rebanhos-bovinos-107461n.aspx $>$. Acesso em 03/10/2017.

Moreira, J. S. Avaliação dos indicadores zootécnicos da atividade leiteira da fazenda pinhal, MG. 38p. Monografia (Graduação). Universidade de Brasília / Faculdade de Agronomia e Medicina Veterinária, 2012.

Oliveira, A. A. Artigo: Desafios para a produção de leite no Nordeste. 2015. Disponível em: < https://www.embrapa.br/busca-denoticias/-Inoticia/2697798/artigo-desafios-para-a-

producao-de-leite-no-nordeste > Acesso em : 30/09/2017

Perotto, D; Abrahão, J. J. S; Kroetz, I. A. Intervalo de partos de fêmeas bovinas Nelore, Guzerá x Nelore, Red Angus x Nelore, Marchigiana x Nelore e Simental x Nelore. Revista Brasileira de Zootecnia, v.35, n.3, p.733-741, 2006. http://dx.doi.org/10.1590/S151635982006000300014

Rangel, A. H. N; Guedes, P. L. C; Albuquerque, R P. F; Novais, L. P. Desempenho produtivo leiteiro de vacas Guzerá. Revista Verde de Agroecologia e Desenvolvimento Sustentável, v.4, n.1, p.85-89, 2009. https://www.gvaa.com.br/revista/index.php/RVADS/artic le/download/153/153

Rodriguez, M. A. P.; Mourão, G. B.; Gonçalves, T. M. Curvas de lactação em vacas leiteiras.
$2010 . \quad$ Disponível em: <
https://www.milkpoint.com.br/radar-
tecnico/melhoramento-genetico/curvas-de-lactacao-emvacas-leiteiras-61359n.aspx $>$ Acesso em 30/09/2017.

FUNDAÇAO ROGER. Fatores influenciadores na queda de produção leiteira. 2017. Disponível em: < http://www.fundacaoroge.org.br/blog/fatoresinfluenciadores-na-queda-de-produ\%C $3 \% \mathrm{~A} 7 \% \mathrm{C} 3 \% \mathrm{~A} 30-$ leiteira >. Acesso em: 20/01/2018.

Salgado, L. F. F.; Cruz, T. M. S.; Takatani, H.; Souza, E. E. G.; Silva, D. M. H. Frias, D. F. R. A Raça Girolando: História, Evolução e Importância no Cenário da Pecuária Leiteira Nacional. Boletim técnico 19, Produção animal UNIBRASIL. 14p. Descalvado, SP Dezembro, 2016.

Santos, E. P. B. Ajustes de curvas de lactação de vacas mestiças das raças Holandesa e Gir. 2012. Dissertação de mestrado - Universidade Federal do Ceará, Fortaleza, 2012.

SNA, Sociedade Nacional da Agricultura. Produtividade da pecuária leiteira é inferior à metade da média mundial. https://www.sna.agr.br/produtividade-da-pecuarialeiteira-e-inferior-a-metade-da-media-mundial/

Zoccal, R. Alguns números do leite. 2016. Disponível em: < http://www.baldebranco.com.br/alguns-numeros-do-leite/ >. Acesso em: 30/09/2017

Zoccal, R. Dez países top no leite. 2017. Disponível em: <http://www.baldebranco.com.br/dezpaises-top-no-leite/ >. Acesso em 30/09/2017 